\title{
МОДЕЛЮВАННЯ ДИСПЕРСІЙНИХ СПІВВІДНОШЕНЬ ПОРИСТИХ КОМПОЗИЦІЙНИХ МА- ТЕРІАЛІВ НА ПІДСТАВІ КОМІРКОВИХ МІКРОРІВНЕВИХ СТРУКТУРНИХ МОДЕЛЕЙ
}

\begin{abstract}
Описано розроблений авторами набір засобів та алгоритмів їх використання для синтезу дисперсійних характеристик мікрорівневих коміркових моделей пористих композиційних матеріалів за допомогою використання інженерної системи числового аналізу COMSOL Multiphysics. Структуру композитів описано комірковими моделями, що будуються у вигляді тривимірних матриць комірок-вокселів. За достатньо великої дискретизації такі моделі дають змогу досліджувати будь-які структурні неоднорідності компонентів композиту. Розроблено засоби та алгоритм синтезу мікрорівневих структурних моделей та їх експорту в промислові інженерні системи числового аналізу методом скінченних елементів. Підсистема експорту базується на форматі даних NASTRAN, що забезпечує високий рівень інтеграції з майже всіма сучасними системами інженерних розрахунків, зокрема, таких, як COMSOL Multiphysics. На підставі моделі системи COMSOL, для дослідження електромагнітних хвиль у частотній області, розроблено алгоритм синтезу дисперсійних співвідношень для елементарних об'ємів композитів із перпендикулярними сторонами, що містять періодичні структури 3 довільною симетрією. Частковим випадком таких об'ємів є мікрорівневі моделі пористих композитів. Такий підхід дає змогу єдиним чином досліджувати багато складних структур, що становить наукову новизну та практичну цінність. Отримані результати добре узгоджуються 3 контрольними прикладами.
\end{abstract}

Ключові слова: структура композитів; числове моделювання; фотонний кристал; дисперсійне співвідношення; COMSOL.

Вступ. Мікрорівневі коміркові моделі композитів використовуються у задачах моделювання та проектування фізичних властивостей матеріалів складної структури. Вони дають змогу на базовому рівні описати всі структурні неоднорідності компонентів композиції та розглядати їх взаємодію в мультифізичних задачах. Їх використання дає змогу адекватно описувати ключовий взаємозв'язок "склад - структура - характеристики" композиційних матеріалів у задачах їх моделювання та проектування [2, 4, 15, 17, 37, 38, 41].

Об'єктом дослідження є пористі діелектричні композиційні матеріали складної періодичної структури.

Предметом дослідження є засоби та алгоритми моделювання дисперсійних співвідношень пористих композиційних матеріалів на підставі коміркових мікрорівневих структурних моделей

Мета дослідження полягає в розробленні методів і засобів для синтезу дисперсійних співвідношень пористих композиційних матеріалів складної структури на підставі числового моделювання задачі поширення електромагнітних хвиль у частотній області в мікрорівневих структурах композитів.

Основними завданнями дослідження є:

1) розроблення засобів експорту мікрорівневих структурних моделей пористих композитів у промислові системи інженерного аналізу для можливості подальшого числового моделювання фізичних процесів у них;

2) розроблення алгоритмів синтезу дисперсійних співвідношень моделей пористих композитів у системі інженерного аналізу, що враховують їхні особливості;

3) верифікація розроблених засобів та алгоритмів їх використання шляхом порівняння отриманих результатів моделювання контрольних прикладів 3 відомими результатами.

Такий підхід вдосконалить наявні моделі та методи синтезу дисперсійних співвідношень та дасть змогу досліджувати єдино широкий клас складних структур композитів, що є науковою новизною, а отримані засоби та алгоритми їх використання становлять практичну ијнність.

Аналіз літературних джерел. Пористі діелектричні композиційні матеріали, що є періодичними структурами, активно використовуються в оптичних пристроях $[1,2,3,8,9,10,11,26,27,28]$. Важливими для розуміння $\epsilon$ їх дисперсійні характеристики, оскільки для будьякої періодичної структури існує діапазон частот хвилевих явищ, за якого внаслідок дисперсії хвиля не здатна пройти крізь цю структуру [25, 27, 29, 39]. Синтез дисперсійних характеристик нетривіальних періодичних структур діелектричних композитів різної топології $\epsilon$ предметом інтересу дослідників, про що свідчить велика кількість публікацій за останні роки $[10,11,26,34,40]$.

Інформація про авторів:

Яворський Назарій Борисович, канд. техн. наук, асистент, кафедра систем автоматизованого проектування.

Email: nazariy.jaworski@gmail.com; https://orcid.org/0000-0003-1312-7302; Scopus ID: 56471722200, ResearcherID: S-4443-2017

Андрущак Назарій Анатолійович, канд. техн. наук, доцент, кафедра систем автоматизованого проектування.

Email: nandrush@gmail.com; https://orcid.org/0000-0002-8248-404X; Scopus ID: 25927837600, ResearcherID: H-1912-2015

Цитування за ДСтУ: Яворський Н. Б., Андрущак Н. А. Моделювання дисперсійних співвідношень пористих композиційних матеріалів на підставі коміркових мікрорівневих структурних моделей. Науковий вісник НлтУ України. 2020, т. 30, № 1. С. $142-151$.

Citation APA: Jaworski, N. B., \& Andrushchak, N. A. (2020). Simulation of dispersion relations of porous composite materials basing on cellular microlevel structural models. Scientific Bulletin of UNFU, 30(1), 142-151. https://doi.org/10.36930/40300125 
Моделювання структури пористих композитів. Мікрорівнева коміркова модель композиційного матеріалу будується у формі елементарних об'ємів, що умовно $є$ тривимірною матрицею скалярних комірок-інтенсивностей в діапазоні від 0 до 1 (рис. 1). Субдіапазони цих інтенсивностей визначають окремі компоненти композиції зі своїми фізичними характеристиками. За достатньо великої кількості таких воксельних елементів-комірок з'являється можливість моделювати будьякі складні структурні неоднорідності компонент [16, $19,20]$.

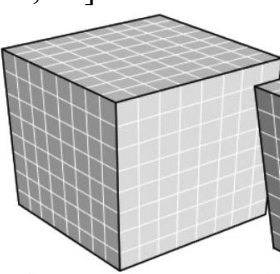

a)

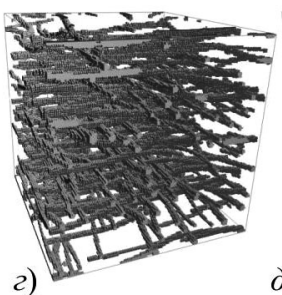

б)

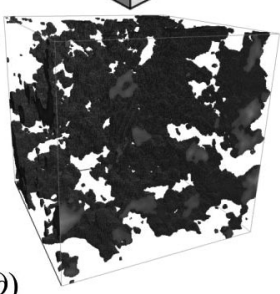

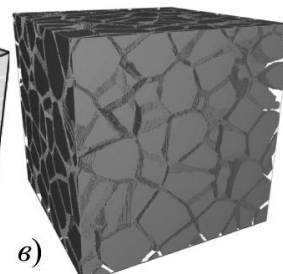

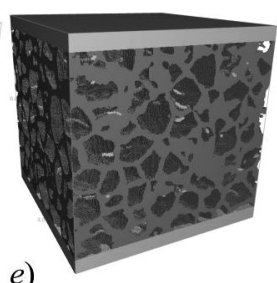

Рис. 1. Умовне зображення елементарних об'ємів мікрорівневих коміркових моделей композитів та опис за допомогою них складних неоднорідних структур, де різний колір відповідає різним компонентам матеріалу

Одна 3 основних переваг мікрорівневих коміркових моделей $\epsilon$ можливість їх безпосереднього використання як дискретизації в подальшому числовому моделюванні фізичних процесів різної природи, зазвичай методом скінченних елементів. Для цього кожні вісім сусідніх комірок об'єднуються у шість скінченних симплекс-елементів. Зазначені обчислення потребують значних часових затрат. Завдяки регулярності та простоті такої дискретизації всі обчислювальні кроки легко піддаються розпаралелюванню [22, 23, 24].

Типовим представником пористих композиційних матеріалів $є$ анодований оксид алюмінію, структуру якого зображено на рис. 2. Наближено таку структуру можна подати за допомогою генерування волокнистих включень зі заданим гексагональним шаблоном (див. рис. 2) $[16,22]$.

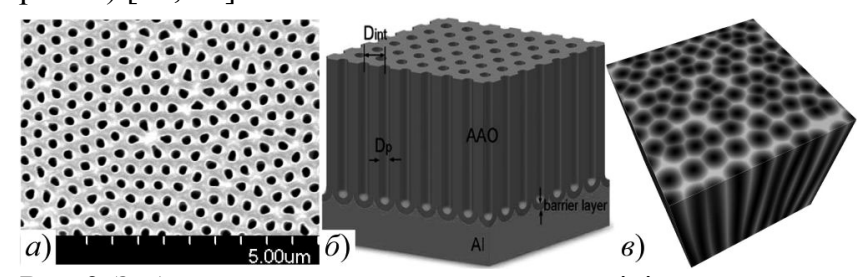

Рис. 2. Зображення анодованого оксиду алюмінію, отримане сканувальним електронним мікроскопом (a) [36]; відповідна схематична модель структури (б) [28]; побудована мікрорівнева коміркова модель структури, де різний колір відповідає різним компонентам матеріалу (в) $[16,22]$

Особливості поширення електромагнітних хвиль у періодичних структурах. Модель електромагнітної хвилі описується відомими рівняннями Максвелла у частотній області, де величини можна подати у формі суперпозиції просторової та гармонічної складової, наприклад $[3,5,7,25]$ :

$$
\begin{gathered}
\mathbf{E}(\mathbf{r}, \tau)=\mathbf{E}(\mathbf{r}) e^{-\mathrm{i} \omega \tau} \text { та } \frac{\partial^{2}\left(\mathbf{E}(\mathbf{r}) e^{-\mathrm{i} \omega t}\right)}{\partial t^{2}}=\omega^{2} \mathbf{E}(\mathbf{r}) e^{-\mathrm{i} \omega t}, \quad \omega=2 \pi f, \\
\frac{1}{\varepsilon} \nabla \times \nabla \times \mathbf{E}=\left(\frac{\omega}{c}\right)^{2} \mathbf{E}, \quad \nabla \times \frac{1}{\varepsilon} \nabla \times \mathbf{H}=\left(\frac{\omega}{c}\right)^{2} \mathbf{H}, \\
\nabla \times \frac{1}{\varepsilon} \nabla \times \mathbf{B}=\left(\frac{\omega}{c}\right)^{2} \mathbf{B}, \quad \nabla \times \nabla \times \frac{1}{\varepsilon} \mathbf{D}=\left(\frac{\omega}{c}\right)^{2} \mathbf{D}, \\
\nabla \cdot \varepsilon \mathbf{E}=0, \quad \nabla \cdot \mathbf{H}=0, \quad \nabla \cdot \mathbf{B}=0, \quad \nabla \cdot \mathbf{D}=0 .
\end{gathered}
$$

Для проведення числового експерименту останні рівняння потрібно доповнити необхідними крайовими умовами. Рівняння (1) $є$ інваріантними відносно масштабування [25]. Задачі, що описуються рівняннями типу (1), є задачами на власні значення [9, 12, 25, 39]. Загальний розв'язок будь-якого рівняння типу (6) можна подати у вигляді функцій виду [5, 39]:

$$
f(\mathbf{r}, t)=\mathbf{A} e^{i(\mathbf{k} \cdot \mathbf{r}-\omega t)},
$$

де: А - амплітуда коливань, що містить інформацію про фазу; k - хвильовий вектор. Амплітуда коливань може визначати поляризацію хвилі, тоді вона стає вектором поляризації. Важливими частковими випадками є лінійні поляризації відносно об'єкта спостереження, що позначаються в літературі ТЕ - коли хвиля поляризована перпендикулярно до площини падіння на об'єкт i TM - коли паралельно. Для різних поляризацій розв'язки вихідної задачі можуть відрізнятися. Решту поляризацій можна представити як лінійну комбінацію цих двох попередніх.

Загалом кутова частота і хвильовий вектор є взаємозалежними. Ця залежність виражається через дисперсійне співвідношення, що $є$ предметом розгляду цієї роботи $[9,25,39]$ :

$$
\omega=\omega(\mathbf{k}) .
$$

Пористі композиційні матеріали, такі як анодований оксид алюмінію, мають періодичну структуру. Перебіг фізичних процесів у періодичних структурах має особливу природу. Її дослідження виконують на ширшому класі метаматеріалів, до яких відносять фотонні кристали $[25,27,29]$. У найпростішому випадку фотонний кристал складається 3 кількох компонентів 3 різними показниками заломлення. Періодичні вкраплення одного компоненту в інший спричиняють утворення, так званих, фотонних смуг пропускання електромагнітної хвилі - фактично її фільтрування за певними частотами внаслідок дисперсії. Коли частина хвилі поширюється через об'єкт із більшим показником заломлення, ця частина затримується. Так, хвиля стає збуреною об'єктом. Хвилі в періодичних структурах набувають такої ж симетрії та періодичності, як і сама структура. Періодичність структури можна описати функцією обгортки. Для цього використовують теорему Блоха [9, 25, 39], за допомогою якої розв'язок рівнянь типу (1) на періодичних структурах можна представити як комбінацію:

$$
\mathbf{E}(\mathbf{r})=\mathbf{E}_{\mathbf{k}}(\mathbf{r}) e^{i \mathbf{k} \cdot \mathbf{r}}
$$

де: $\mathbf{E}_{\mathbf{k}}(\mathbf{r})$ - це періодична функція обгортки, що описує структуру; $\mathbf{k}$ - це хвилевий вектор Блоха. Підставляючи (4) в (1), отримаємо $[9,11,25,39]$ :

$$
\begin{gathered}
\frac{1}{\varepsilon} \nabla \times \nabla \times \mathbf{E}_{\mathbf{k}} e^{i \mathbf{k} \cdot \mathbf{r}}=\left(\frac{\omega}{c}\right)^{2} \mathbf{E}_{\mathbf{k}} e^{i \mathbf{k} \cdot \mathbf{r}} \Rightarrow \\
\Rightarrow \frac{1}{\varepsilon}(\nabla+\mathrm{i} \mathbf{k}) \times(\nabla+\mathrm{i} \mathbf{k}) \times \mathbf{E}_{\mathbf{k}}=\left(\frac{\omega}{c}\right)^{2} \mathbf{E}_{\mathbf{k}} .
\end{gathered}
$$

Щоб дізнатися який діапазон хвилевих векторів варто досліджувати, доцільно розглянути примітивні ко- 
мірки - певний об'єм у структурі, визначений так, щоб його трансляцією можна було б відтворити всю структуру, і який водночас, характеризується всіма елементами симетрії цієї структури. Найчастіше їх розглядають у контексті оберненої гратки, для якої знаходиться незменшувана зона Бріллюена (irreducible Brillouin zone, IBZ) - область оберненого векторного простору, зменшена максимально шляхом відкидання внутрішніх симетрій (рис. 3).

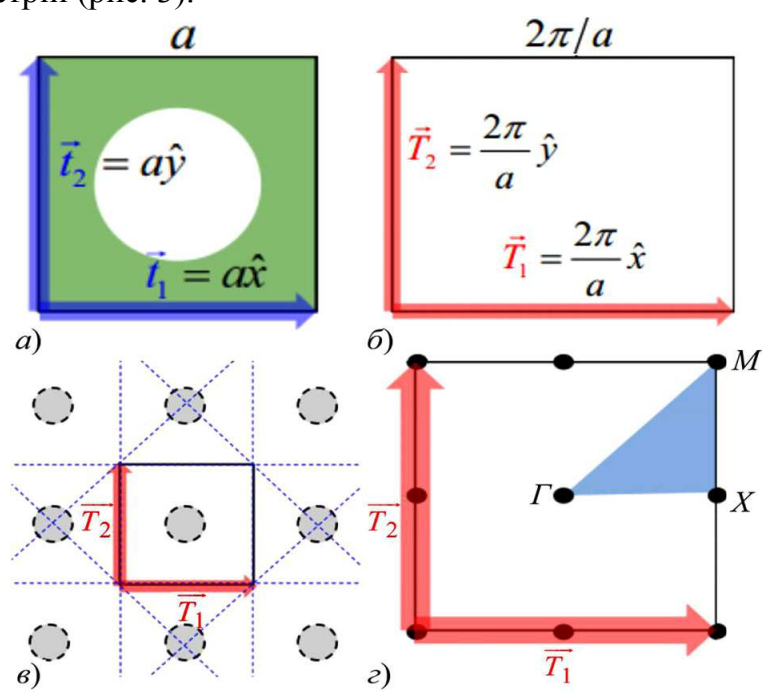

Рис. 3. Приклад прямої ( $a$ ) та оберненої (б) граток періодичної структури та ії першої зони Бріллюена (в) [35], а також незменшувана зона Бріллюена (2) з відповідними вузлами симетрії [33]

На рис. 3,2 розмір елементарної комірки позначено як $a$, ключові вузли симетрії $\Gamma, X$ та $M$ утворюються лінійною комбінацією векторів оберненої гратки:

$$
\Gamma=\left[\begin{array}{l}
0 \\
0
\end{array}\right], \quad X=\frac{1}{2} \mathbf{T}_{1}, \quad M=\frac{1}{2} \mathbf{T}_{1}+\frac{1}{2} \mathbf{T}_{2}, \quad \mathbf{T}_{1}=\mathbf{T}_{2}=\frac{2 \pi}{a} .
$$
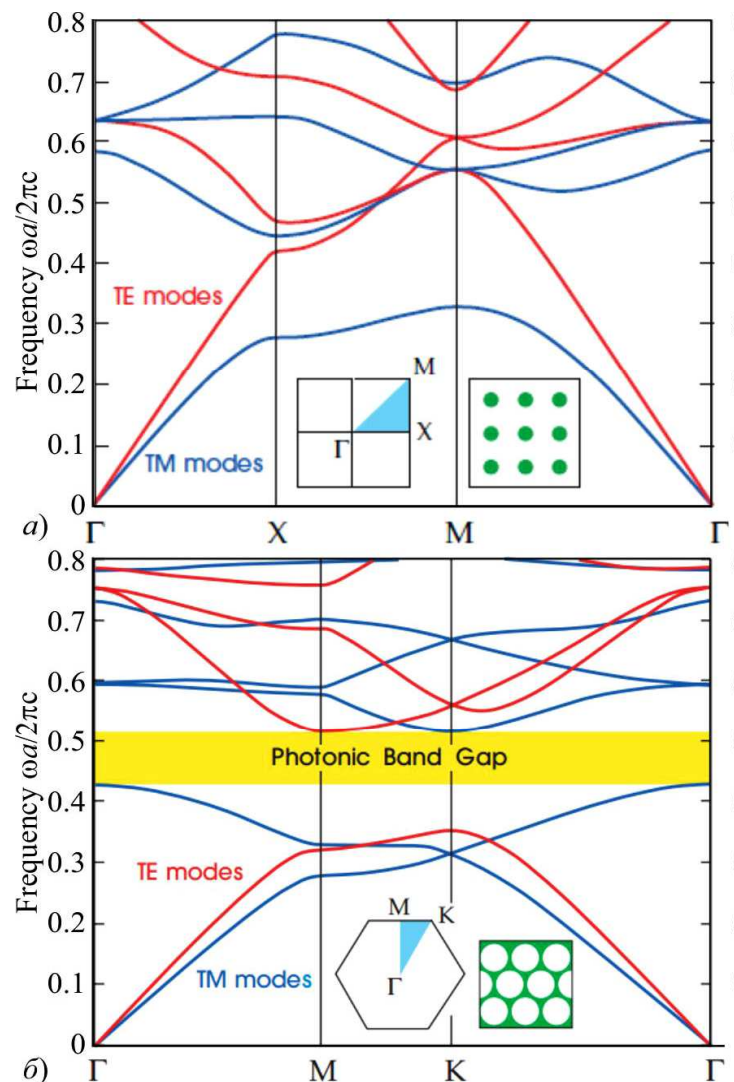

Для того, щоб отримати достатньо інформації про дисперсійне співвідношення $\omega(\mathbf{k})$ на певній періодичній структурі, потрібно розглянути хвилеві вектори Блоха $\mathbf{k}$ по периметру незменшуваної зони Бріллюена.

Гексагональна теселяція має іншу незменшувану зону Бріллюена. Приклад іiі знаходження наведено на рис. 4. Ключові вузли симетрії $\Gamma, M$ та $K$ утворюються лінійною комбінацією векторів оберненої гратки:

$$
\mathbf{T}_{1}=\left[\begin{array}{c}
\frac{2 \pi}{a} \\
-\frac{2 \pi}{a \sqrt{3}}
\end{array}\right], \mathbf{T}_{2}=\left[\begin{array}{c}
\frac{2 \pi}{a} \\
+\frac{2 \pi}{a \sqrt{3}}
\end{array}\right], \Gamma=\left[\begin{array}{l}
0 \\
0
\end{array}\right], M=\frac{1}{2} \mathbf{T}_{2}, K=\frac{1}{3} \mathbf{T}_{1}+\frac{1}{3} \mathbf{T}_{2} .
$$

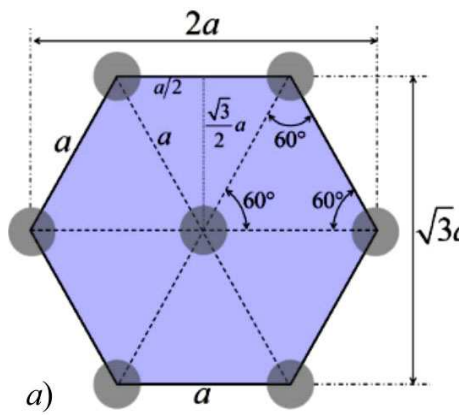

б)

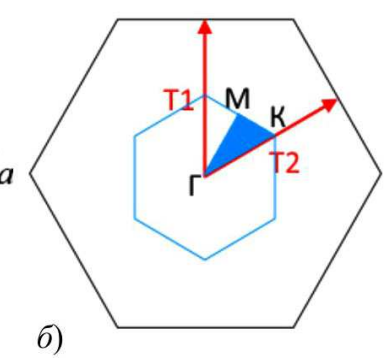

Рис. 4. Незменшувана зона Бріллюена та іiі ключові вузли симетрії для гексагональної теселяції

На рис. 5 зображено еталонну [25] діаграму пропускання хвиль (дисперсійне співвідношення) $\omega(\mathbf{k})$ для двовимірної періодичної структури та її відтворення за допомогою системи COMSOL Multiphysics для різних поляризацій. Кожна крива (смуга пропускання електромагнітних хвиль) на рисунку утворена 3 власних значень розв'язків рівняння (5).
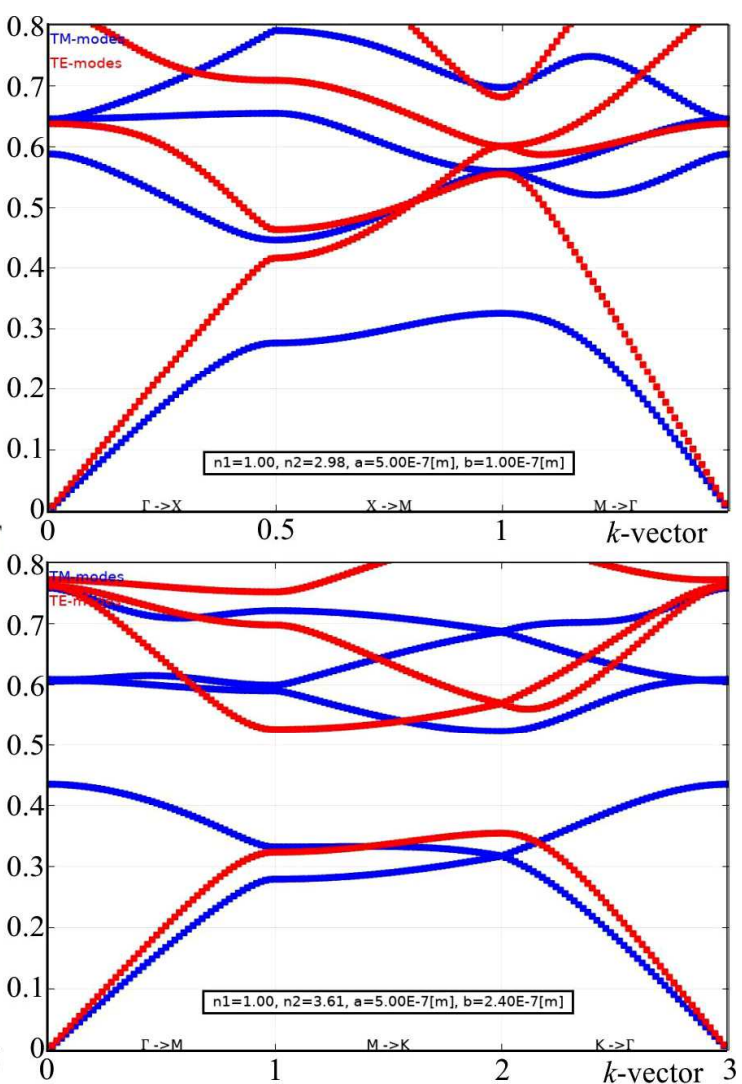

Рис. 5. Приклад порівняння результатів знаходження дисперсійних співвідношень для двовимірних періодичних структур: $a$ ) періодична структура квадратного масиву стовпців оксиду алюмінію $(\varepsilon=8,9)$ в повітрі $(\varepsilon=1)$; б) періодична структура гексагонального масиву повітряних дір $(\varepsilon=1)$ у діелектрику $(\varepsilon=13)$ 
Будь-яке електромагнітне поле, що може утворитися у такій структурі, можна описати як лінійну комбінацію наведених розв'язків. Ліворуч еталонні значення взято з [25], праворуч - отримано значення в системі COMSOL Multiphysics.

Як видно $з$ рис. 5, $а$ для заданої конфігурації періодичної структури квадратного масиву стовпців діелектрику в повітрі спостерігаємо провал у ТМ-поляризації для частот близько $0,4 a$ / $(2 \pi c)$. Це означає, що будь-яке електромагнітне поле зазначеної поляризації за заданої частоти буде само гаситися внаслідок дисперсії, тобто структура не пропускає електромагнітну хвилю цієї частоти та поляризації. Провал є частковий, оскільки смуги ТЕ-поляризація в цій області присутні. Проте 3 рис. 5,б також видно, що для заданої конфігурації періодичної структури гексагонального масиву повітряних дір у діелектрику спостерігаємо провал в обох поляризаціях для частот близько $0,475 a /(2 \pi c)$, тобто структура не пропускає жодну електромагнітну хвилю вказаної частоти незалежно від поляризації. Докладно фізичну природу цих явищ описано в [25]. Там також наведено атлас провалів смуг пропускання для різних періодичних структур, зокрема, на рис. 6 зображено карту провалів смуг пропускання гексагонального масиву повітряних дір у діелектрику для різних конфігурацій структури композиту, якими є пористі композиційні матеріали, а також карту смуг пропускання гексагонального масиву діелектричних стовпців у повітрі.

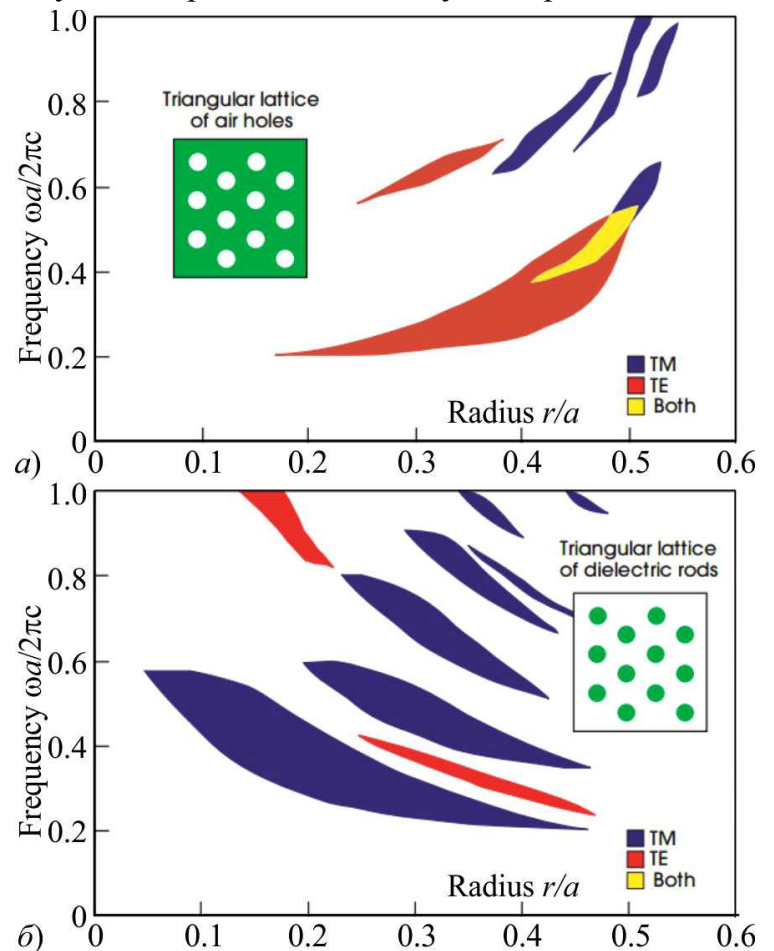

Рис. 6. Карта провалів смуг пропускання гексагонального масиву повітряних дір у діелектрику $(a)$ та діелектричних стовпців у повітрі (б) [25]

\section{Матеріал і методи дослідження}

Експорт структурної моделі. Дослідження явищ різної фізичної природи в композитах складної структури проводиться на підставі моделювання відповідних задач деякими числовими методами. Одним із найбільш розвинених у цьому плані $є$ метод скінченних елементів, реалізацію якого надають провідні системи інженерного моделювання, а також спеціалізовані системи.
Для того, щоб мати можливість використовувати такі інструменти, автори розробили підсистему експорту мікрорівневих коміркових структурних моделей композитів у формат системи NASTRAN (Nastran BDF - bulk data format), який де-факто $\epsilon$ відкритим стандартом для промислових скінченно-елементних обчислень і забезпечує високий рівень інтеграції з майже всіма сучасними системами інженерних розрахунків [18, 31, 32].

Модель деякої фізичної задачі, що має бути розв'язана числовим методом, можна задати вхідним текстовим файлом, що містить форматовані записи - Nastran BDF файл [31]. Інформацією, що експортується, є координати вузлів дискретизації, скінченні елементи, що об'єднують ці вузли та розподіл елементів на окремі компоненти-матеріали. Опис процедури експорту тривимірної мікрорівневої коміркової моделі композитів наведено в [18]. Для експорту двовимірних моделей необхідно виконати такі дії:

1. Оголосити секцію даних комбінацією ключових слів "BEGIN, BULK". Секція завершується ключовим словом "ENDDATA". Основними частинами цієї секції є: вузли, елементи, системи координат, характеристики матеріалів, матеріали, обмеження та параметри аналізу. Порядок задання даних не важливий.

2. Оголосити матеріали ключовим словом "МАТ1" з вказанням "material identification number, MID", наприклад "MAT1,1".

3. Оголосити властивості матеріалу ключовим словом "PSHELL" $з$ вказанням "property identification number, PID" та MID, що відповідає номеру відповідного MAT1, наприклад "PSHELL, 1,1".

4. Визначити топологію моделі шляхом задання вузлів дискретизації в тривимірному просторі (третя координата дорівнює 0). Ключове слово "GRID" визначає точку в просторі з вказанням "identification number, ID"; "identification number of coordinate system, CP" (цей параметр варто залишити очевидно пустим); координати точки "X1", "X2" та "X3". Наприклад "GRID, 1, ,0,0,0".

5. Завершити визначення топології шляхом задання скінченних елементів. Ключове слово "CTRIA3" визначає двовимірний трикутний симплекс чи навіть комплекс елементів із вказанням: "element identification number, EID"; PID, що відповідає номеру відповідного PSHELL; номерами визначених вузлів "G1", "G2" та "G3". Наприклад "CTRIA3,1,1,1,2,3".

На рис. 7 наведено приклад примітивного Nastran BDF файлу, що описує двокомпонентний ламінат.

Синтез дисперсійних співвідношень. Синтез дисперсійних співвідношень пористих композитів у системі COMSOL Multiphysics базується переважно на роботах $[6,8]$. Розглянемо періодичну структуру квадратного масиву стовпців діелектрику $(\varepsilon=8,9)$ в повітрі $(\varepsilon=1)$, що зображені на рис. 5,a. Для прикладу, розмір комірки $a$ взято 500 нм. Результати є інваріантними відносно масштабування, тому цей розмір може бути дещо іншим. Система COMSOL Multiphysics дає змогу знайти власні значення рівнянь у напруженості електричного поля типу (5).
$B E G I N, B U L K$
$M A T 1,1$
PSHELL, 1, 1
$M A T 1,2$
PSHELL $, 2,2$
GRID $1,1,0,0,0$
GRID $, 2,1,0,0$
GRID $3,2,0,0$ 


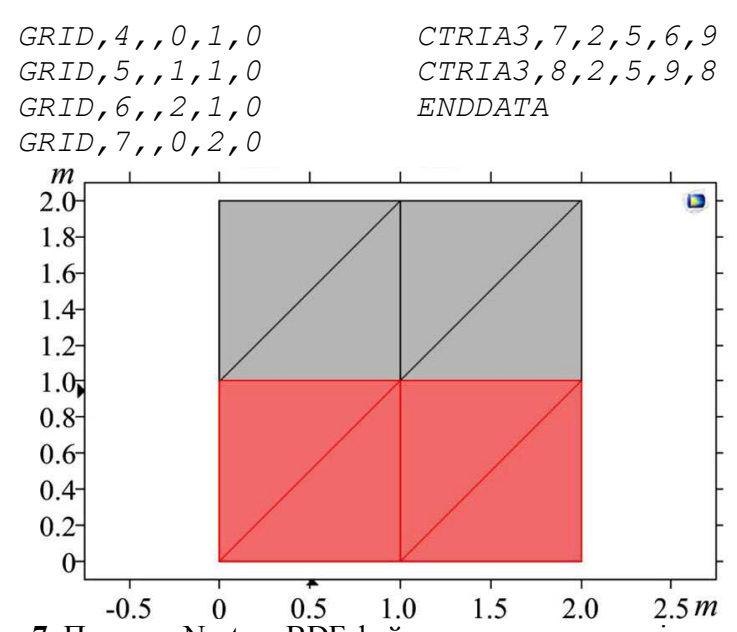

Рис. 7. Приклад Nastran BDF файлу, що описує примітивний двокомпонентний ламінат і його візуалізація в системі СОМSOL Multiphysics

Для побудови дисперсійних співвідношень потрібно здійснити такі кроки:

1. Створити в системі COMSOL Multiphysics нову двовимірну модель.

2. Додати до неї фізичну модель дослідження електромагнітних хвиль у частотній області (Electromagnetic Waves, Frequency Domain), що $є$ інтерфейсом оптики (Optics) $\rightarrow$ хвилевої оптики (Wave Optics). Необхідно додати два такі інтерфейси для синтезу окремих дисперсійних відношень для ТМ та ТЕ поляризацій відповідно.

3. Оголосити глобальні параметри:

\begin{tabular}{|c|c|l|}
\hline$a$ & $=500[\mathrm{~nm}]$ & - розмір примітивної комірки; \\
\hline$b$ & $=0,2 \cdot \mathrm{a}$ & - радіус стовпця; \\
\hline$k$ & $=0$ & $\begin{array}{l}\text { параметр для перебору хвилевих векто- } \\
\text { рів Блоха; }\end{array}$ \\
\hline$k$ Step & $=0,01$ & $\begin{array}{l}\text { - крок між сусідніми хвилевими вектора- } \\
\text { ми Блоха; }\end{array}$ \\
\hline$n 1$ & $=1$ & $\begin{array}{l}\text { - показник заломлення першої компонен- } \\
\text { ти композиту; }\end{array}$ \\
\hline$n 2$ & $=\operatorname{sqrt}(8,9)$ & $\begin{array}{l}\text { - показник заломлення другої компонен- } \\
\text { ти композиту; }\end{array}$ \\
\hline$n$ Bands & $=4$ & $\begin{array}{l}- \text { кількість необхідних смуг дисперсійних } \\
\text { співвідношень. }\end{array}$ \\
\hline
\end{tabular}

4. Визначити функції обходу хвилевих векторів Блоха по периметру незменшуваної зони Бріллюена (див. рис $3,2)$. Для цього на підставі (6) потрібно визначити дві кускові функції $k x()$ та $k y()$ для $x$ та $y$ координати (ix та відповідні їм крайові умови будемо називати "прямокутними" через форму елементарної комірки):

\begin{tabular}{|c|c|c|c|c|c|}
\hline \multicolumn{3}{|c|}{$k x(x)$} & \multicolumn{3}{c|}{$k y(x)$} \\
\hline Початок & Кінець & Функція & Початок & Кінець & Функція \\
\hline 0 & 0,5 & $x$ & 0 & 0,5 & 0 \\
\hline 0,5 & 1 & 0,5 & 0,5 & 1 & $x-0,5$ \\
\hline 1 & 1,5 & $1,5-x$ & 1 & 1,5 & $1,5-x$ \\
\hline
\end{tabular}

Функції визначені на відрізку від 0 до 1,5, в межах якого буде змінюватися глобальний параметр $k 3$ кроком $k$ Step. Число 1,5 обрано з розрахунку, що для обходу трьох відрізків між вузлами симетрії $\Gamma, X, M$, параметр $k$ змінюватиметься від 0 до 0,5 , бо такий коефіцієнт присутній у формулі (6).

5. Створити геометрію примітивної комірки. Для цього визначити прямокутник зі сторонами $a$, що відповідає умовному домену 1 , та коло з радіусом $b$, що розміщене в центрі та відповідає умовному домену 2.

6. Визначити характеристики матеріалів із показниками заломлення $n_{1}$ та $n_{2}$ відповідно. Матеріал вважаємо ізотропним, тому внутрішні компоненти тензору дорівнюють: $n \_$iso $=n 1 ; n i i=n \_i s o, n i j=0$. Уявну частину показника заломлення приймаємо рівною нулю - $k i$ iso $=0 ; k i i i=k i$ iso, $k i i j=0$.

7. Визначити фізичну модель дослідження електромагнітних хвиль у частотній області для ТЕ-поляризації. Для цього $з$ налаштувань за бажанням потрібно змінити:

- форму рівняння (Equation form) на частотну область (Frquency domain);

- розв'язки компонент електричного поля (Electric field components solved for) на вектор у площині (In-plane vector).

Окрім цього, потрібно визначити періодичні крайові умови, що задають необхідний перебір хвилевих векторів Блоха по периметру елементарної комірки. У системі COMSOL Multiphysics вони задаються за допомогою крайових умов типу Флоке [7, 12]. Варто задати дві крайові умови на кожну пару протилежних сторін квадратної елементарної комірки. Сама крайова умова визначається на підставі рівняння (6) покомпонентно через попередньо визначені функції $k x()$ та $k y()$.

8. Визначити фізичну модель дослідження електромагнітних хвиль у частотній області для ТМ-поляризації 3 тією різницею, що розв'язки компонент електричного поля (Electric field components solved for) потрібно змінити на вектор поза площиною (Out-of-plane vector).

9. Здійснити дискретизацію.

10. Налаштувати параметри розв'язку фізичної задачі (Study) на власні значення (Eigenfrequency). Для цього потрібно визначити два окремі кроки розв'язку (Study step) для ТM- та ТЕ-поляризацій відповідно. В обох випадках варто зазначити:

- ручний метод пошуку власних частот (Eigenfrequency search method - Manual);

- бажану кількість власних частот (Desiered number of eigenfrequencies), рівну параметру $n B a n d s$;

- пошук власних частот (Eigenfrequency search method around shift) довкола більших дійсних частин (Larger real part) - це дає змогу не розглядати комплексні власні значення;

- допоміжну зміну (Auxiliary sweep) параметру $k$ з кроком $k$ Step на відрізку від 0 до 1,5.

11. Здійснити розв'язок фізичної задачі. Внаслідок буде отримано набір дійсних власних частот для визначених параметрів, а також відповідне їм наближення електромагнітного поля в межах елементарної комірки.

12. Оформити результати у вигляді дисперсійних співвідношень (див. рис. 5). Для цього потрібно додати глобальний графік (1D Plot Group $\rightarrow$ Global plot), де по осі $y$ варто відкласти знайдені нормалізовані власні частоти як ewfdTM.freq·alc_const, а по осі $x$ - значення параметру $k$.

Особливості дослідження гексагональних структур. Як видно з формули (7) та рис. 4, елементарні комірки структур із гексагональною теселяцією мають іншу симетрію. Для синтезу не надлишкових дисперсійних співвідношень необхідно змінити відповідні функції обходу хвилевих векторів Блоха по периметру незменшуваної зони Бріллюена. Для цього на підставі (7) потрібно визначити дві інші кускові функції $k x()$ та $k y()$ для $x$ та $y$ координати (їх та відповідні їм крайові умови називатимемо "оригінальними").

Розглянемо випадок, коли за низкою обставин сторони елементарної комірки повинні бути прямокутними. Деякі дослідники пропонують використовувати для цього афінні перетворення [13], що дають змогу зберегти такий же шаблон дисперсійних співвідношень, що й оригінальні. У протилежному випадку, смуги пропускання електромагнітних хвиль зміняться, але не змінюючи при цьому розміщення провалів. Іншими словами, 
ми отримаємо лінійну комбінацію оригінальних співвідношень, що несе в собі таку ж корисну інформацію.

Якщо розглядати не єдину елементарну комірку, а деяку їхню сукупність, яку в літературі називають суперкоміркою і часто використовують для дослідження різних дефектів у періодичній структурі $[1,9,25]$, то отримані дисперсійні співвідношення будуть містити надлишкові смуги. Їхня кількість буде пропорційна кількості елементарних комірок у суперкомірці. Знову ж таки отримані надлишкові смуги є лінійною комбінацією оригінальних співвідношень і тому отримані результати також несуть в собі корисну інформацію.

На рис. 8,a зображено структуру суперкомірки та відповідну їй діаграму дисперсійних співвідношень, синтезовану в системі COMSOL Multiphysics, що містить надлишкові смуги (див. рис. 8,б). Комірка складається 3 двох примітивних комірок по осі $y$. Якщо порівняти діаграми на рис. 8,6 і рис. 6,б, то можна зауважити, що кількість смуг пропускання подвоїлася. Особливо це помітно в діапазоні частот під провалом. Крайові умови оригінальні [33, 35].

В отриманих результатах втрачають свій зміст вузли симетрії $\Gamma, M, K$. Оскільки комірка тепер прямокутна, до неї можна застосувати відповідні описані вище "прямокутні" функції $k x()$ та $k y()$, змінивши область їх визначення з відрізку від 0 до 1,5 на відрізок від 0 до 3 . Окрім цього, потрібно змінити крайові умову типу Флоке на $k x(k) \cdot 2 \cdot p i / a$ та $k y(k) \cdot 2 \cdot p i /(a \cdot s q r t(3) / 2) / 2$.

Продовжуючи міркування, побудуємо дисперсійні співвідношення для суперкомірок із гексагональною теселяцією, що максимально наближені до квадратних. Оскільки елементарна комірка має розмір $1 \times \sqrt{3} / 2$, то най-
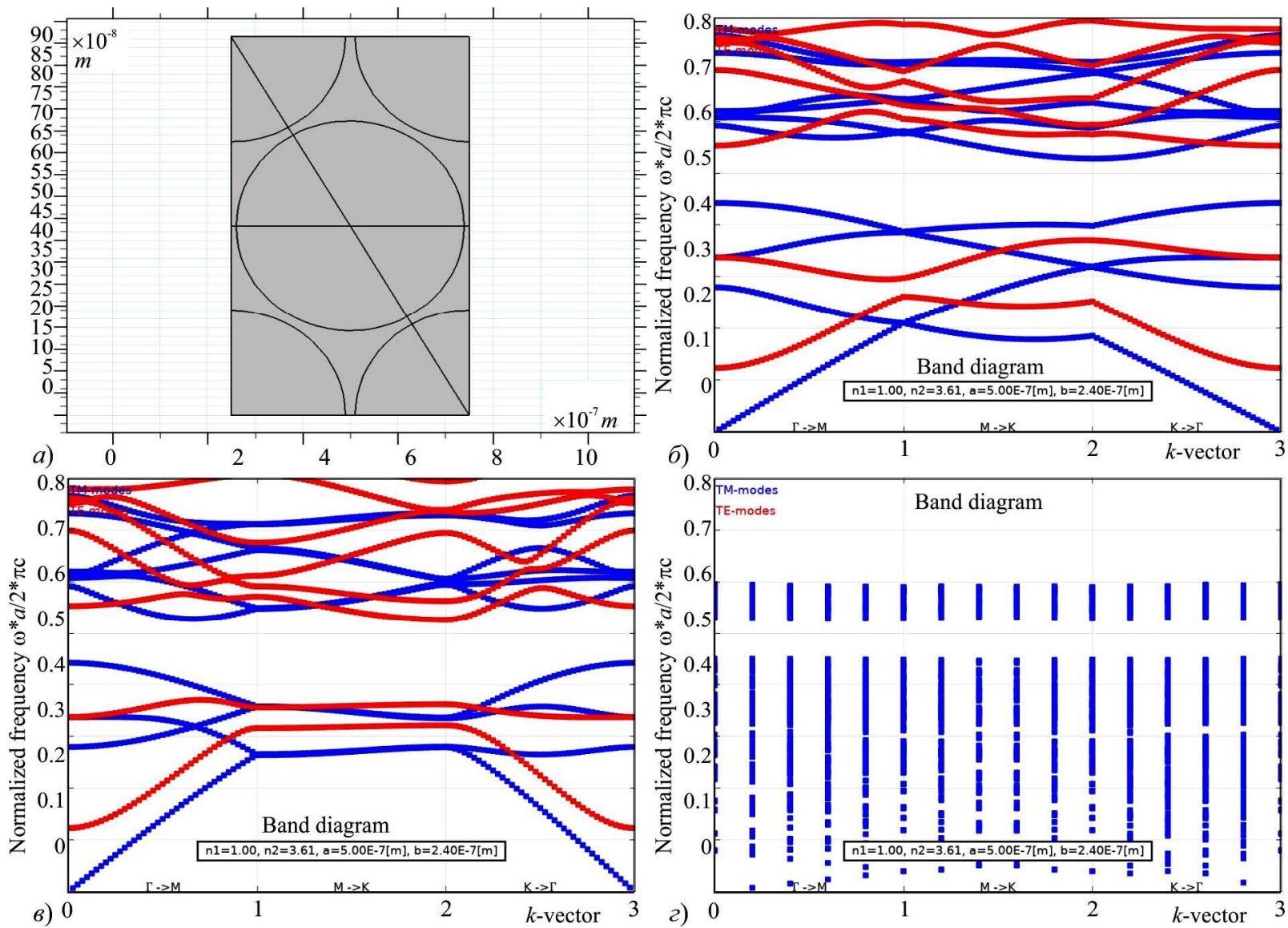

Рис. 8. Структура суперкомірки $1 \times 2(a)$ гексагонального масиву повітряних дір у діелектрику та відповідна їй діаграма дисперсійних співвідношень 3 надлишковістю за оригінальних крайових умов (б), за "прямокутних" крайових умов (в), а також діаграма дисперсійних співвідношень суперкомірки 7×8 (2) (показано тільки ТМ-поляризацію) 

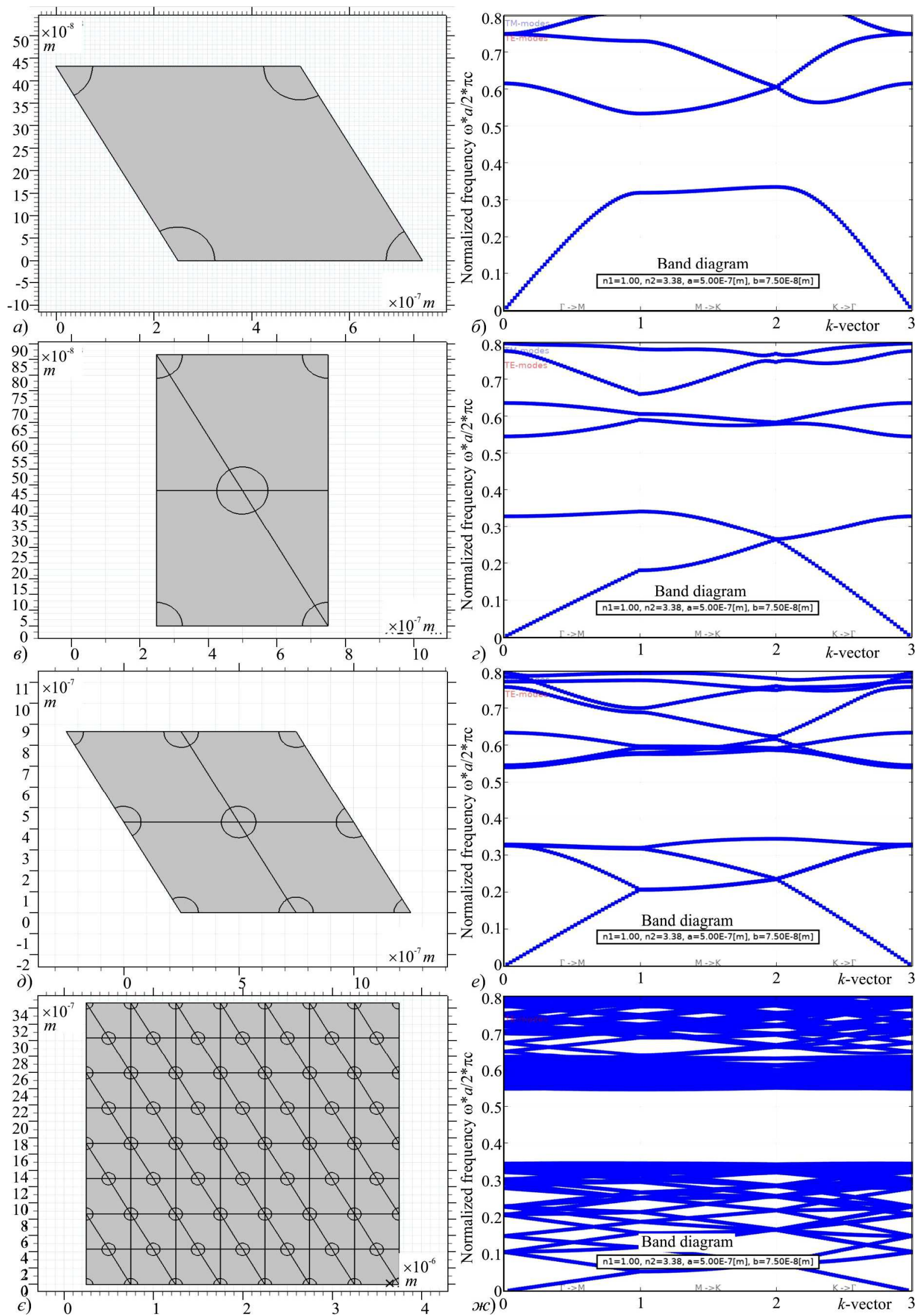

e) 0

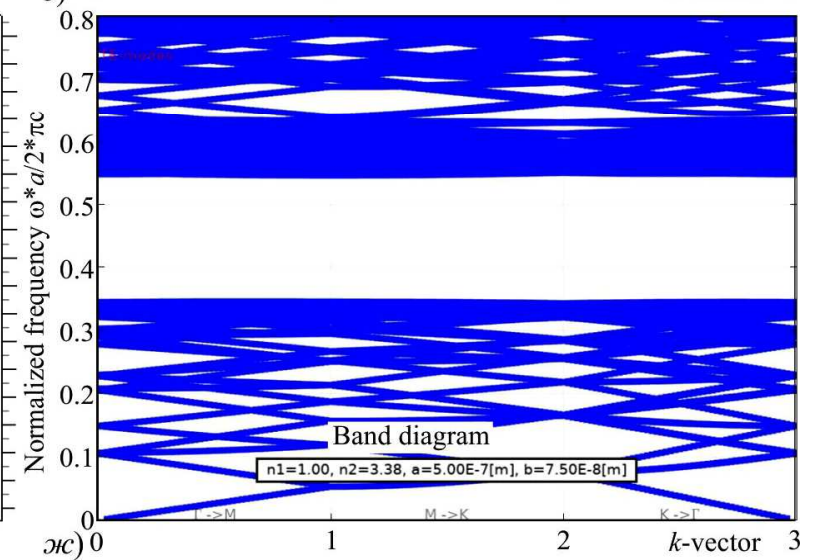

Рис. 9. Діаграми дисперсійних співвідношень для різних комірок масиву гексагональних стовпців діелектриків $(\varepsilon=11,4)$ у повітрі $(\varepsilon=1)$, радіус стовпців $b=0,15 a$

Розмір примітивної комірки $a$ становить 500 нм. Вона описує гексагональну теселяцію. Розмір суперкомірки, побудованої як наближення $7 \times 8$ примітивних, дорівнює 3,5 мкм. Діри вважаються заповненими повітрям $(\varepsilon=1)$, діелектрична проникність діелектрика $\varepsilon=11,4$. Крайові умову типу Флоке $\epsilon$ "прямокутні" та описують-

ся функціями $k x(k) \cdot 2 \cdot p i / a / 7$ та $k y(k) \cdot 2 \cdot p i / a / 7$. На рис. 10 зображено синтезовані дисперсійні співвідношення для ТЕ-поляризації, що добре узгоджуються з контрольними прикладами та картою рис. $6, a$. У діапазоні частот між $0,3 a /(2 \pi c)$ та $0,45 a /(2 \pi c)$ чітко видно провал. 


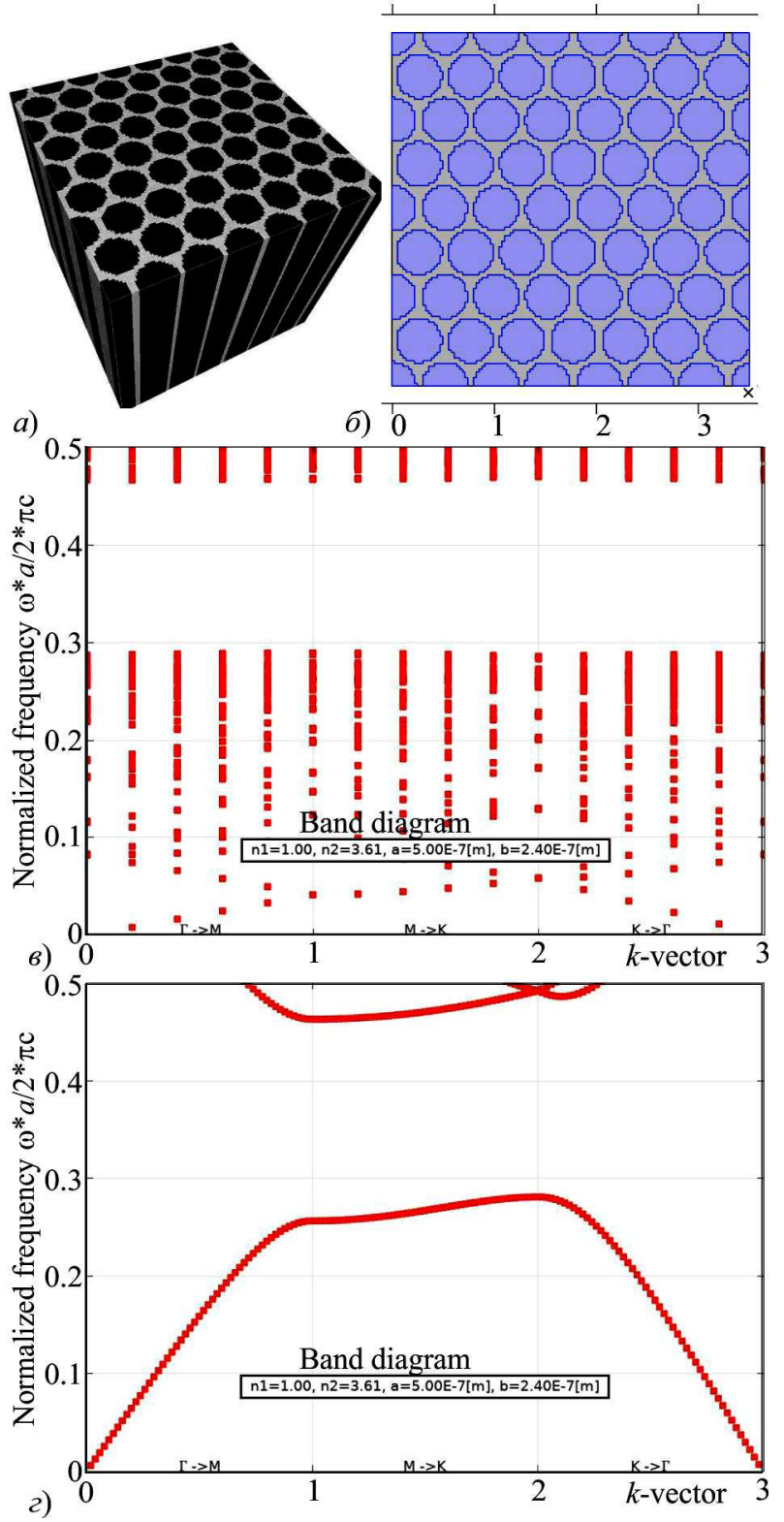

Рис. 10. Імпорт структурної мікрорівневої коміркової моделі пористого композиту $(a)$, збережена у форматі Nastran BDF, в систему COMSOL Multiphysics (б), діаграма дисперсійних співвідношень для ТЕ-поляризації (в), контрольна діаграма примітивної комірки (2), радіус пор $b=0,4375 a$, діелектрична проникність діелектрика $\varepsilon=11,4$ і пори $\varepsilon=1$

Висновки. Розроблено алгоритми та запропоновано засоби для синтезу дисперсійних співвідношень пористих композиційних матеріалів складної структури на підставі числового моделювання задачі поширення електромагнітних хвиль у частотній області в мікрорівневих структурах композитів.

Мікрорівнева структура композитів описується комірковими воксельними моделями, що дає змогу за достатньої дискретизації досліджувати будь-які структурні неоднорідності компонентів матеріалів.

Розроблено засоби та алгоритм синтезу мікрорівневих структурних моделей та їх експорту в промислові інженерні системи числового аналізу методом скінченних елементів. Підсистема експорту двовимірних мікрорівневих коміркових структурних моделей композитів забезпечує високий рівень інтеграції з майже всіма сучасними системами інженерних розрахунків.

Розроблено алгоритм синтезу дисперсійних співвідношень для мікрорівневих моделей за допомогою сис- теми COMSOL Multiphysics. Для цього використовується модель системи COMSOL для дослідження електромагнітних хвиль у частотній області та знаходження власних значень рівнянь в напруженостях електричного поля, що надалі формують дисперсійні криві.

Розроблено алгоритм синтезу дисперсійних співвідношень для елементарних комірок із перпендикулярними сторонами, що містять періодичні структури 3 довільною симетрією, частковим випадком яких $є$ мікрорівневі моделі пористих композитів. Отримані результати добре узгоджуються 3 контрольними прикладами. Такий підхід дає змогу єдиним чином досліджувати багато складних композиційних структур і становить наукову новизну та практичну цінність.

Подяка. Ця робота була виконана за підтримки Міністерства освіти та науки України в рамках проекту ДБ/СубТера (номер держреєстрації 0119U100609).

\section{References}

1. Andonegui, I., \& Garcia-Adeva, A. (2013). The finite element method applied to the study of two-dimensional photonic crystals and resonant cavities. Optic express, 21(4), 4072-4092. https://doi.org/10.1364/OE.21.004072

2. Andrushchak, N., Jaworski, N., \& Lobur, M. (2017). Improvement of the numerical method for effective refractive index calculation of porous composite materials using microlevel models. (Ser. A). Acta Physica Polonica, 133(1), 164-166. https://doi.org/10.12693/APhysPolA.133.164

3. Armstrong, E., \& O'Dwyer, C. (2015). Artificial opal photonic crystals and inverse opal structures - fundamentals and applications from optics to energy storage. Journal of Materials Chemistry C, 3(24), 6109-6143. https://doi.org/10.1039/c5tc01083g

4. Bargmann, S., Klusemann, B., Markmann, J., Schnabel, J., et al. (2018). Generation of 3D representative volume elements for heterogeneous materials: A review. Progress in Materials Science, 96, 322-384. https://doi.org/10.1016/i.pmatsci.2018.02.003

5. Chen, C. L. (2007). Foundations for Guided-Wave Optics - Hoboken. New Jersey: Wiley \& Sons.

6. Computing the Bandgap of a 2D Photonic Crystal by COMSOLMATLAB Scripting. (2018). Retrieved from: https://github.com/xiumingzhang/photonic-bandgap-comsol-matlab.

7. COMSOL 5.4 Wave Optics Module User's Guide. (2018). Retrieved from: https://doc.comsol.com/5.4/doc/com.comsol.help.woptics/WaveOpticsModuleUsersGuide.pdf.

8. COMSOL Multiphysics 5.4. Band-Gap Analysis of a Photonic Crystal. (2018). Retrieved from: https://www.comsol.ru/model/band-gap-analysis-of-a-photonic-crystal-798.

9. Danner, A. (2011). An introduction to the plane wave expansion method for calculating photonic crystal band diagrams. Retrieved from: https://www.ece.nus.edu.sg/stfpage/eleadj/planewave.htm.

10. Fathollahi Khalkhali, T., \& Bananej, A. (2016). Effect of shape of scatterers and plasma frequency on the complete photonic band gap properties of two-dimensional dielectric-plasma photonic crystals. Physics Letters A, 380(48), 4092-4099. https://doi.org/10.1016/j.physleta.2016.10.012

11. Fietz, C., Urzhumov, Y., \& Shvets, G. (2011). Complex k band diagrams of 3D metamaterial/photonic crystals. Opt. Express 19(20), 19027-19041. https://doi.org/10.1364/OE.19.019027

12. Gantmacher, F. (1966). Matrix Theory. (2nd ed., suppl. in Russian). Moscow: Science.

13. Guo, S., \& Albin, S. (2003). Simple plane wave implementation for photonic crystal calculations. Optics express, 11(2), 167-175. https://doi.org/10.1364/OE.11.000167

14. Hakoda, C., Rose, J., Shokouhi, P., \& Lissenden, C. (2018). Using Floquet periodicity to easily calculate dispersion curves and wave structures of homogeneous waveguides. AIP Conference Proceedings, 1949, 020016. https://doi.org/10.1063/1.5031513

15. Jaworski, N. (2015). Effective Thermal Characteristics Synthesis Microlevel Models in the Problems of Composite Materials Opti- 
mal Design. ECONTECHMOD: an international quarterly journal on economics of technology and modelling processes, 4(2), 312. Retrieved from: https://yadda.icm.edu.pl/yadda/element/bwmeta1.element.baztech-aecf75f6-7fd7-4184-9c00bea9083632cc.

16. Jaworski, N., \& Andrushchak, N. (2017). A method of nanoporous anodic aluminum oxide structure modeling based on Bezier curves generation. 14th International Conference The Experience of Designing and Application of CAD Systems in Microelectronics (CADSM 2017), (pp. 63-66), Lviv, Ukraine, 2017. https://doi.org/10.1109/CADSM.2017.7916085

17. Jaworski, N., \& Andrushchak, N. (2018). The numerical method for effective refractive index calculation of porous composite materials based on microlevel models. Scientific Bulletin of UNFU, 28(6), 140-146. https://doi.org/10.15421/40280628

18. Jaworski, N., Andrushchak, N., Lobur, M., Iwaniec, M., \& Sitek, W. (2019). Composite Material Microlevel Cellular Model Data Transfer and Verification by FEM Analysis Software Systems. IEEE 15th International Conference on the Perspective Technologies and Methods in MEMS Design (MEMSTECH), (pp. 17-22), Polyana, Ukraine,

2019 .

https://doi.org/10.1109/MEMSTECH.2019.8817376

19. Jaworski, N., Farmaga, I., \& Marikutsa, U. (2015). Building the Micro-Level Composite Materials Structure Models in the Problems of their Optimal Design. Scientific Bulletin of UNFU, 25(8), 359-366. https://doi.org/10.15421/40250858

20. Jaworski, N., Farmaga, I., \& Marikutsa, U. (2015). Random transition layers construction method and its application in heterogeneous structures multiscale modelling by OpenCL technology. (Ser. Computer Science and Information Technologies). Bulletin $L P N U, \quad 826, \quad 385-394 . \quad$ Retrieved from: https://ena.lp.edu.ua:8080/handle/ntb/31340.

21. Jaworski, N., Farmaga, I., Lobur, M., \& Spiewak, P. (2013). Research of composite materials optimal design task based on numerical simulation. Proc. of the 8th Int. Scientific and Technical Conference Computer Sciences and Information Technologies (CSIT'2013), (pp. 46-48). Lviv.

22. Jaworski, N., Iwaniec, M., \& Lobur, M. (2017). Implementation features of fibrous composite microlevel structure model construction based on bezier curves generation and OpenCL technology usage. Machine Dynamics Research, 41(3), 47-62. Retrieved from: https://yadda.icm.edu.pl/baztech/element/bwmeta1.element.baztech-16225ce6-ee1f-42c6-8f5a-9cbde7abefe5.

23. Jaworski, N., Iwaniec, M., \& Lobur, M. (2019). Implementation Features of Composite Materials Effective Mechanical Characteristics Finding Method Based on Microlevel Cellular Structural Models. IEEE 15th International Conference on the Experience of Designing and Application of CAD Systems (CADSM), (pp. 1-5), Polyana, Ukraine,

2019.

https://doi.org/10.1109/CADSM.2019.8779273

24. Jaworski, N., Lobur, M., \& Iwaniec, M. (2018). Implementation features of cellular composites microlevel structural models construction based on Voronoi tessellation and OpenCL technology usage. 14th International Conference on Perspective Technologies and Methods in MEMS Design (MEMSTECH), (pp. 109-113), Lviv, Ukraine, 2018 https://doi.org/10.1109/MEMSTECH.2018.8365713
25. Joannopoulos, J., Johnson, S., Winn, J., \& Meade, R. (2008). Photonic Crystals. Molding the Flow of Light. (2nd ed.). Princeton University Press.

26. Li, S., Lin, H., Meng, F., Moss, D., et al. (2018). On-Demand Design of Tunable Complete Photonic Band Gaps based on Bloch Mode Analysis. Scientific Reports, 8, 14283. https://doi.org/10.1038/s41598-018-32422-1

27. Lin, T. R., Lin, C. H., \& Hsu, J. C. (2013). Enhanced acousto-optic interaction in two-dimensional phoxonic crystals with a line defect. Journal of Applied Physics, 113, 053508. https://doi.org/10.1063/1.4790288

28. Losic, A. (2015). Nanoporous Alumina. Fabr., Str., Prop. and App. NY: Springer, $371 \mathrm{p}$.

29. Ma, T. X., Zou, K., Wang, Y. S., Zhang, C., \& Su, X. X. (2014). Acousto-optical interaction of surface acoustic and optical waves in a two-dimensional phoxonic crystal hetero-structure cavity. $\mathrm{Op}$ tics 22(23), Express, 28443-28451. https://doi.org/10.1364/OE.22.028443

30. Morozov, G., \& Sprung, D. (2011). Floquet-Bloch waves in onedimensional photonic crystals. EPL (Europhysics Letters), 96(5), 54005-p1. https://doi.org/10.1209/0295-5075/96/54005

31. MSC Software. MSC Nastran 2012 Quick Reference Guide. (2012). Retrieved from: https://simcompanion.mscsoftware.com/infocenter/index?page $=$ content\&id=DOC10004.

32. Quartus Engineering. An Employee-Owned Company, NASTRAN 101. Retrieved from: https://www.quartus.com/resources/nastran$101 /$.

33. Rumpf, R. (2012). ECE 5322: 21-st Century Electromagnetics. Retrieved from: https://emlab.utep.edu/ee5390cem.htm.

34. Segovia-Chaves, F., Vinck-Posada, H., \& Navarro-Barón, E. (2019). Photonic band structure in a two-dimensional hexagonal lattice of equilateral triangles. Physics Letters A, 383(25), 32073213. https://doi.org/10.1016/j.physleta.2019.07.020

35. Szabó, B., \& Babuška, I. (2011). Introduction to Finite Element Analysis. Formulation, Verification and Validation. New-York: Wiley.

36. Technical Data Sheet ACS Material Single-Pass AAO Templates. Retrieved from: https://www.acsmaterial.com/single-pass-aao-5pack-1277.html.

37. Torquato, S. (2002). Random Heterogeneous Materials. Microstructure and Macroscopic Properties. New-York: Springer.

38. Wang, M., \& Pan, N. (2008). Predictions of effective physical properties of complex multiphase materials. International Journal Materials Science and Engineering: $R, \quad 63(1), \quad 1-30$. https://doi.org/10.1016/j.mser.2008.07.001

39. Yariv, A., \& Yeh, P. (1984). Optical Waves in Crystals. Propagation and Control of Laser Radiation. John Wiley \& Sons. 604 p. Retrieved from: https://www.wiley-vch.de/en/areasinterest/engineering/optical-waves-in-crystals-978-0-471-43081-0

40. Zhang, Z., Fan Li, Y., Meng, F., \& Huang, X. (2017). Topological design of phononic band gap crystals with sixfold symmetric hexagonal lattice. Computational Materials Science, 139, 97-105. https://doi.org/10.1016/j.commatsci.2017.07.037

41. Zohd, T. (2018). 1Rapid Voxel-Based Digital-Computation for Complex Microstructured Media. Arch. of Comp. Meth. in Eng., 1-16. https://doi.org/10.1007/s11831-018-9284-1

N. B. Jaworski, N. A. Andrushchak

Lviv Polytechnic National University, Lviv, Ukraine

\section{SIMULATION OF DISPERSION RELATIONS OF POROUS COMPOSITE MATERIALS BASING ON CELLULAR MICROLEVEL STRUCTURAL MODELS}

Porous dielectric composite materials, which are periodic structures, are actively used in optical devices. Essential for understanding is their dispersion characteristics because, for any periodic structure, there is a range of frequencies of the wave at which due to the dispersion, it is not able to pass through such a structure. Research is usually carried out on a broader class of metamaterials to which photonic crystals belong. In the simplest case, a photonic crystal consists of several components with different refractive indices. Periodic inclusions of one component into another cause the formation of so-called electromagnetic wave transmission band gaps. That is filtering at specific frequencies. The synthesis of dispersion characteristics of nontrivial periodic structures of dielectric composites with various topologies is the topical interest to researchers, as evidenced by a large number of publications of the scien- 
tific community in recent years. In this paper, authors have discussed a set of tools and algorithms, which they have developed to synthesize the dispersion characteristics of microlevel cellular models of composite materials by using the engineering system for numerical analysis COMSOL Multiphysics. The structure of the composites is described by cellular microlevel models which are threedimensional matrixes of voxel cells. With a large number of such voxels, it is possible to simulate any complex structural heterogeneity. Tools and algorithms of synthesis of microlevel structural models and their export to industrial engineering systems of numerical analysis based on the finite element method are developed. The export subsystem is based on the NASTRAN data format, which provides a high level of integration with almost all modern engineering systems, such as COMSOL Multiphysics. Based on the COMSOL model for the study of electromagnetic waves in the frequency domain, the algorithm for the synthesis of dispersion relations for elementary volumes with perpendicular sides containing periodic structures with arbitrary symmetry has been developed. A partial case of those elementary volumes are microlevel models of porous composites. This approach makes it possible to explore in a single way a wide range of complex structures, which brings scientific novelty and practical value.

Keywords: composite structure; numerical simulation; photonic crystal; dispersion relation; COMSOL. 